\title{
Model sensitivity studies of the decrease in atmospheric carbon tetrachloride
}

Martyn P. Chipperfield ${ }^{1,2}$, Qing Liang ${ }^{3,4}$, Matthew Rigby ${ }^{5}$, Ryan Hossaini ${ }^{6}$, Stephen A. Montzka ${ }^{7}$, Sandip Dhomse $^{1}$, Wuhu Feng ${ }^{1,8}$, Ronald G. Prinn ${ }^{9}$, Ray F. Weiss ${ }^{10}$, Christina M. Harth ${ }^{10}$, Peter K. Salameh ${ }^{10}$, Jens Mühle ${ }^{10}$, Simon O'Doherty ${ }^{5}$, Dickon Young ${ }^{5}$, Peter G. Simmonds ${ }^{5}$, Paul B. Krummel ${ }^{11}$, Paul J. Fraser ${ }^{11}$, L. Paul Steele ${ }^{11}$, James D. Happell ${ }^{12}$, Robert C. Rhew ${ }^{13}$, James Butler ${ }^{7}$, Shari A. Yvon-Lewis ${ }^{14}$, Bradley Hall ${ }^{7}$, David Nance ${ }^{7}$, Fred Moore $^{7}$, Ben R. Miller ${ }^{7}$, James W. Elkins ${ }^{7}$, Jeremy J. Harrison ${ }^{15,16}$, Chris D. Boone ${ }^{17}$, Elliot L. Atlas ${ }^{18}$, and Emmanuel Mahieu ${ }^{19}$

${ }^{1}$ School of Earth and Environment, University of Leeds, Leeds, LS2 9JT, UK

${ }^{2}$ National Centre for Earth Observation, University of Leeds, Leeds, LS2 9JT, UK

${ }^{3}$ NASA Goddard Space Flight Center, Atmospheric Chemistry and Dynamics, Greenbelt, Maryland 20771, USA

${ }^{4}$ Universities Space Research Association, GESTAR, Columbia, Maryland 21046, USA

${ }^{5}$ Atmospheric Chemistry Research Group, School of Chemistry, University of Bristol, Bristol, BS8 1TS, UK

${ }^{6}$ Lancaster Environment Centre, Lancaster University, Lancaster, LA1 4YQ, UK

${ }^{7}$ Global Monitoring Division, NOAA Earth System Research Laboratory, Boulder, Colorado 80305, USA

${ }^{8}$ National Centre for Atmospheric Science, University of Leeds, Leeds, LS2 9JT, UK

${ }^{9}$ Massachusetts Institute of Technology, Cambridge, Massachusetts 02139 USA

${ }^{10}$ Scripps Institution of Oceanography, University of California San Diego, La Jolla, California 92093-0244, USA

${ }^{11}$ CSIRO Oceans and Atmosphere, Aspendale, Victoria 3195, Australia

${ }^{12}$ Department of Ocean Sciences, University of Miami, Florida 33149, USA

${ }^{13}$ Departmet of Geography, University of California, Berkeley, California 94720-4740, USA

${ }^{14}$ Department of Oceanography, Texas A\&M University, College Station, Texas 77840, USA

${ }^{15}$ Department of Physics and Astronomy, University of Leicester, Leicester, LE1 7RH, UK

${ }^{16}$ National Centre for Earth Observation, University of Leicester, Leicester, LE1 7RH, UK

${ }^{17}$ Department of Chemistry, University of Waterloo, Ontario, N2L 3G1, Canada

${ }^{18}$ Department of Atmospheric Sciences, University of Miami, Miami, Florida 33149, USA

${ }^{19}$ Institute of Astrophysics and Geophysics, University of Liège, Liège 4000, Belgium

Correspondence to: Martyn P. Chipperfield (m.chipperfield@leeds.ac.uk)

Received: 9 July 2016 - Published in Atmos. Chem. Phys. Discuss.: 18 August 2016

Revised: 24 November 2016 - Accepted: 28 November 2016 - Published: 20 December 2016

\begin{abstract}
Carbon tetrachloride $\left(\mathrm{CCl}_{4}\right)$ is an ozone-depleting substance, which is controlled by the Montreal Protocol and for which the atmospheric abundance is decreasing. However, the current observed rate of this decrease is known to be slower than expected based on reported $\mathrm{CCl}_{4}$ emissions and its estimated overall atmospheric lifetime. Here we use a three-dimensional (3-D) chemical transport model to investigate the impact on its predicted decay of uncertainties in the rates at which $\mathrm{CCl}_{4}$ is removed from the atmosphere by photolysis, by ocean uptake and by degradation in soils. The
\end{abstract}

largest sink is atmospheric photolysis ( $74 \%$ of total), but a reported $10 \%$ uncertainty in its combined photolysis cross section and quantum yield has only a modest impact on the modelled rate of $\mathrm{CCl}_{4}$ decay. This is partly due to the limiting effect of the rate of transport of $\mathrm{CCl}_{4}$ from the main tropospheric reservoir to the stratosphere, where photolytic loss occurs. The model suggests large interannual variability in the magnitude of this stratospheric photolysis sink caused by variations in transport. The impact of uncertainty in the minor soil sink ( $9 \%$ of total) is also relatively small. In contrast, 
the model shows that uncertainty in ocean loss (17\% of total) has the largest impact on modelled $\mathrm{CCl}_{4}$ decay due to its sizeable contribution to $\mathrm{CCl}_{4}$ loss and large lifetime uncertainty range (147 to 241 years). With an assumed $\mathrm{CCl}_{4}$ emission rate of $39 \mathrm{Gg} \mathrm{year}^{-1}$, the reference simulation with the best estimate of loss processes still underestimates the observed $\mathrm{CCl}_{4}$ (overestimates the decay) over the past 2 decades but to a smaller extent than previous studies. Changes to the rate of $\mathrm{CCl}_{4}$ loss processes, in line with known uncertainties, could bring the model into agreement with in situ surface and remote-sensing measurements, as could an increase in emissions to around $47 \mathrm{Gg}$ year ${ }^{-1}$. Further progress in constraining the $\mathrm{CCl}_{4}$ budget is partly limited by systematic biases between observational datasets. For example, surface observations from the National Oceanic and Atmospheric Administration (NOAA) network are larger than from the Advanced Global Atmospheric Gases Experiment (AGAGE) network but have shown a steeper decreasing trend over the past 2 decades. These differences imply a difference in emissions which is significant relative to uncertainties in the magnitudes of the $\mathrm{CCl}_{4}$ sinks.

\section{Introduction}

Carbon tetrachloride $\left(\mathrm{CCl}_{4}\right)$ is an important ozone-depleting substance (ODS) and greenhouse gas (GHG) (WMO, 2014). Because of its high ozone depletion potential (ODP), it has been controlled since the 1990 London Amendment to the 1987 Montreal Protocol. Historically $\mathrm{CCl}_{4}$ was used as a solvent, as a fire-retarding chemical and as a feedstock for production of chlorofluorocarbons (CFCs) and their replacements, though current production should be limited to feedstock, process agents and other essential applications (WMO, 2014).

In response to the controls of dispersive uses under the Montreal Protocol and its adjustments and amendments, the atmospheric burden of $\mathrm{CCl}_{4}$ peaked at around $106 \mathrm{ppt}$ $\left(\mathrm{pmol} \mathrm{mol}^{-1}\right)$ in 1990 and then declined at about $1 \mathrm{ppt} \mathrm{year}^{-1}$ (around $1 \%$ year $^{-1}$ ) through 2005 with indications of a faster rate of decline, around 1.3 ppt year $^{-1}$, since then. Carpenter et al. (2014) give the recent rate of decline (2011-2012) as 1.1-1.4 ppt year $^{-1}$, depending on the observation network. However, despite this ongoing decline in atmospheric $\mathrm{CCl}_{4}$ burden there is a significant discrepancy in the known $\mathrm{CCl}_{4}$ budget. The atmospheric decline is significantly slower than would be expected based on reported production to dispersive and non-dispersive uses, and current estimates of the strength of $\mathrm{CCl}_{4}$ sinks.

The main removal process for atmospheric $\mathrm{CCl}_{4}$ is slow transport to the stratosphere followed by photolysis at UV wavelengths (see Burkholder et al., 2013). This photolysis mainly occurs in the middle stratosphere, and so the rate of removal depends also on the slow transport of $\mathrm{CCl}_{4}$ through the stratosphere by the Brewer-Dobson circulation, for which the speed can vary. The other significant sinks for $\mathrm{CCl}_{4}$ are ocean uptake (Krysell et al., 1994) and degradation in soils (Happell and Roche, 2003; Happell et al., 2014).

Uncertainties in the $\mathrm{CCl}_{4}$ budget, where emissions derived from reported production magnitudes underestimate the sources needed to be consistent with our understanding of $\mathrm{CCl}_{4}$ loss processes and its change in atmospheric abundance, have been an issue for almost 2 decades. These uncertainties have been highlighted in many of the 4-yearly World Meteorological Organization (WMO)/United Nations Environmental Programme (UNEP) ozone assessments, including the most recent one in 2014. WMO (2014) stated that estimated sources and sinks of $\mathrm{CCl}_{4}$ remain inconsistent with observations of its abundance. The report used an overall atmospheric $\mathrm{CCl}_{4}$ lifetime of 26 years to infer a need for 57 (40-74) $\mathrm{Gg}_{\text {year }}{ }^{-1}$ emissions of $\mathrm{CCl}_{4}$, which greatly exceeded that expected based on reported production for dispersive uses.

Liang et al. (2014) used a three-dimensional (3-D) chemistry-climate model (CCM) to investigate possible causes for this "budget gap" in $\mathrm{CCl}_{4}$. They performed a series of experiments with different assumptions of $\mathrm{CCl}_{4}$ emissions and overall atmospheric lifetime. In particular they used the observed interhemispheric gradient (IHG) of $\mathrm{CCl}_{4}$ to infer the magnitude of ongoing emissions missing in the current inventories, with some information on their distribution between the hemispheres. They inferred that the mean global emissions of $\mathrm{CCl}_{4}$ were 39 (34-45) $\mathrm{Gg}_{\text {year }}{ }^{-1}$ and the corresponding overall $\mathrm{CCl}_{4}$ lifetime was 35 (32-37) years. In contrast their model calculated an overall atmospheric lifetime of $\mathrm{CCl}_{4}$ of 25.8 years, based on a calculated partial lifetime for photolysis loss of 47 years and specified partial lifetimes for ocean and soil loss of 79 and 201 years, respectively.

The partial lifetime of $\mathrm{CCl}_{4}$ due to loss by photolysis was calculated in the recent Stratospheric Processes And their Role in Climate (SPARC) lifetimes report (SPARC, 2013; Chipperfield et al., 2013) using six chemistry-climate models. The modelled steady-state $\mathrm{CCl}_{4}$ partial lifetime for year2000 conditions varied from 41.4 to 54.3 years with a mean of 49.9 years. The large spread in model values was attributed to different circulation rates in the models; generally a faster tropical upwelling circulation gave rise to a shorter lifetime. To obtain an overall recommended photolysis lifetime value of 44 years, SPARC (2013) combined those model results with a shorter lifetime of 40 years based on stratospheric tracer-tracer correlations and the loss of $\mathrm{CCl}_{4}$ relative to CFC-11 $\left(\mathrm{CFCl}_{3}\right)$.

Since the publication of Liang et al. (2014) there has been renewed interest in the $\mathrm{CCl}_{4}$ budget gap. Rhew and Happell (2016) re-evaluated the global $\mathrm{CCl}_{4}$ soil sink using new observations and an improved land cover classification scheme. They derived the partial lifetime of $\mathrm{CCl}_{4}$ with respect to soil loss to be 375 (288-536) years. Similarly, Butler et al. (2016) have also recently revised the partial lifetime of 
the ocean sink to be 183 (147-241) years. Note that this estimate of the ocean sink is different to the earlier value of 210 (157-313) years provided by the same authors for the recent SPARC report on carbon tetrachloride (SPARC, 2016) prior to their most recent analysis. These partial lifetimes for the soil and ocean sink are both much longer than previous estimates used in Liang et al. (2014), as recommended in Carpenter et al. (2014). The recent papers also provide a revised uncertainty range which can be used to constrain model-data comparisons.

The aim of this paper is to quantify the magnitude of $\mathrm{CCl}_{4}$ emissions over the recent past using the most up-to-date information on the main $\mathrm{CCl}_{4}$ loss processes using the framework of a particular 3-D model. In particular, we use the estimated uncertainties in the $\mathrm{CCl}_{4}$ loss processes to further constrain the likely range of emissions. We also test the results of Liang et al. (2014) using a different model of atmospheric chemistry and transport which we compare to a range of available observations, thereby contributing to more robust conclusions. Section 2 describes the $\mathrm{CCl}_{4}$ observations that we use and our 3-D chemical transport model (CTM). Section 3 compares our model simulations with these observations and quantifies the emissions required for model-data agreement. Section 3 also discusses our results in the context of other recent work. Our conclusions are presented in Sect. 4.

\section{$2 \mathrm{CCl}_{4}$ observations and 3-D model}

\subsection{NOAA and AGAGE $\mathrm{CCl}_{4}$}

We have used surface $\mathrm{CCl}_{4}$ observations from 11 National Oceanic and Atmospheric Administration/Earth System Research Laboratory (NOAA/ESRL) cooperative global air sampling sites (Hall et al., 2011) and 5 sites from the Advanced Global Atmospheric Gases Experiment (AGAGE) network (Simmonds et al., 1998; Prinn et al., 2000, 2016; http://agage.mit.edu/) over 1995-2015 (Table 1). NOAA observations consist of paired air samples collected in flasks approximately weekly and sent to Boulder, Colorado, for analysis by gas chromatography with electron capture detection (GC-ECD), and they are reported on the NOAA-2008 scale. NOAA global and hemispheric averages are computed by weighting station data by cosine of latitude. Actual NOAA station latitudes are used, except for South Pole, for which we use $70.5^{\circ} \mathrm{S}$. AGAGE observations are made at a $40 \mathrm{~min}$ frequency using GC-ECD instruments located at remote sites and are reported on the Scripps Institution of Oceanography 2005 scale (SIO-05). AGAGE data were filtered to remove above-baseline "pollution" events using the method outlined in O'Doherty et al. (2001), and the remaining baseline mole fractions were averaged each month. AGAGE hemispheric and global averages were calculated using the AGAGE 12box model and the method described in Rigby et al. (2014).
Briefly, semi-hemispheric monthly-mean AGAGE baseline data were used to constrain emissions with the model. Global average mole fractions were extracted from the a posteriori forward model run.

\subsection{ACE}

The Atmospheric Chemistry Experiment-Fourier transform spectrometer (ACE-FTS) is on the SCISAT satellite, which was launched in early 2004. ACE-FTS uses the sun as a light source to record limb transmission through the Earth's atmosphere ( $\sim 300 \mathrm{~km}$ effective length) during sunrise and sunset ("solar occultation"). ACE-FTS covers the spectral region 750 to $4400 \mathrm{~cm}^{-1}$ with a resolution of $0.02 \mathrm{~cm}^{-1}$ and can measure vertical profiles for more trace species than any other satellite instrument, although it only records spectra for, at most, 30 occultation events per day (Bernath, 2017). Carbon tetrachloride is one of the species routinely available in the latest v3.5 processing; however the retrieved profiles are biased high by up to $\sim 20-30 \%$ (Allen et al., 2009; Brown et al., 2011; Harrison et al., 2016).

Recently, an improved ACE-FTS $\mathrm{CCl}_{4}$ retrieval has been devised (Harrison et al., 2016), and this will form the basis for the upcoming processing version 4.0 of ACE-FTS data. This preliminary retrieval, which is used here, is available for 527 occultations measured during March and April 2005. The improvements include (a) new high-resolution infrared absorption cross sections for air-broadened carbon tetrachloride; (b) a new set of microwindows which avoid spectral regions where the line parameters of interfering species do not adequately calculate the measured ACE-FTS spectra; (c) the addition of new interfering species missing from v3.5, e.g. peroxyacetyl nitrate (PAN); and (d) an improved instrumental lineshape designed for the upcoming v4.0 processing.

\subsection{NDACC column $\mathrm{CCl}_{4}$ observations}

Carbon tetrachloride can also be retrieved from highresolution infrared solar spectra recorded at ground-based stations. A total column time series spanning the 19992015 period, updated to be consistent with Rinsland et al. (2012), is available from the Jungfraujoch station (Swiss Alps, $46.5^{\circ} \mathrm{N}, 8^{\circ} \mathrm{E}, 3580 \mathrm{~m}$ a.s.1.) and will be used here, but an effort is ongoing to retrieve $\mathrm{CCl}_{4}$ from other NDACC sites (Network for the Detection of Atmospheric Composition Change; see http://www.ndacc.org).

Rinsland et al. (2012) provide a thorough description of the approach which allows the retrieval of $\mathrm{CCl}_{4}$ total columns from ground-based FTIR (Fourier transform infrared) solar absorption spectra. Briefly, the strong $\mathrm{CCl}_{4} \nu_{3}$ band at $794 \mathrm{~cm}^{-1}$ is used, and a broad window spanning the 785$807 \mathrm{~cm}^{-1}$ spectral range is fitted, accounting for main interferences by $\mathrm{H}_{2} \mathrm{O}, \mathrm{CO}_{2}$ and $\mathrm{O}_{3}$, as well as by a dozen second- and third-order absorbers. In particular, it has been shown that line-mixing effects in the strong $\mathrm{CO}_{2}$ Q-branch 
Table 1. List of NOAA and AGAGE stations which provided $\mathrm{CCl}_{4}$ observations.

\begin{tabular}{|c|c|c|c|c|c|}
\hline Site code & Site name & Latitude $\left({ }^{\circ} \mathrm{N}\right)$ & Longitude $\left({ }^{\circ} \mathrm{E}\right)$ & Altitude $(\mathrm{km})$ & Network \\
\hline ALT & Alert, Canada & 82.5 & -62.5 & 0.2 & NOAA \\
\hline BRW & Barrow, USA & 71.3 & -156.6 & 0.01 & NOAA \\
\hline MHD & Mace Head, Ireland & 53.3 & -9.9 & 0.01 & NOAA/AGAGE \\
\hline NWR & Niwot Ridge, USA & 40.1 & -105.6 & 3.5 & NOAA \\
\hline THD & Trinidad Head, USA & 41.1 & -124.1 & 0.1 & NOAA/AGAGE \\
\hline KUM & Cape Kumukahi, USA & 19.5 & -154.8 & 0.02 & NOAA \\
\hline MLO & Mauna Loa, USA & 19.5 & -155.6 & 3.4 & NOAA \\
\hline $\mathrm{RPB}$ & Ragged Point, Barbados & 13.2 & -59.4 & 0.02 & AGAGE \\
\hline SMO & Tutuila, American Samoa & -14.3 & -170.6 & 0.04 & NOAA/AGAGE \\
\hline $\mathrm{CGO}$ & Cape Grim, Australia & -40.7 & 144.7 & 0.09 & NOAA/AGAGE \\
\hline PSA & Palmer Station, USA & -64.9 & -64.0 & 0.01 & NOAA \\
\hline SPO & South Pole, USA & -90.0 & 0 & 2.81 & NOAA \\
\hline
\end{tabular}

at $791 \mathrm{~cm}^{-1}$ have to be accounted for and properly modelled by the retrieval algorithm when dealing with such a widewindow approach. The associated error budget indicates total random and systematic uncertainties on individual total column measurements of less than 7 and $11 \%$, respectively.

\subsection{HIPPO data}

In situ measurements of $\mathrm{CCl}_{4}$ obtained during the HIAPER Pole-to-Pole (HIPPO) aircraft mission have also been considered (Wofsy, 2011; Wofsy et al., 2012). HIPPO consisted of a series of five campaigns over the Pacific Basin using the National Science Foundation (NSF) Gulfstream V aircraft: HIPPO-1 (January 2009), HIPPO-2 (November 2009), HIPPO-3 (March/April 2010), HIPPO-4 (June 2011) and HIPPO-5 (August/September 2011). Across the campaigns, sampling spanned a large latitude range, extending from near the North Pole to coastal Antarctica, and from the surface to $\sim 14 \mathrm{~km}$. Measured $\mathrm{CCl}_{4}$ mixing ratios were derived from analysis of whole-air samples using GC-MS (mass spectrometry) by both NOAA/ESRL and the University of Miami from both pressurised glass and stainless-steel flasks. Results from both laboratories were provided on a scale consistent with NOAA/ESRL.

\subsection{TOMCAT 3-D chemical transport model}

We have used the TOMCAT global atmospheric 3-D off-line CTM (Chipperfield, 2006) to model atmospheric $\mathrm{CCl}_{4}$. The TOMCAT simulations were forced by winds and temperatures from the 6-hourly European Centre for Medium-Range Weather Forecasts (ECMWF) ERA-Interim reanalyses (Dee et al., 2011). The simulations covered the period 1996 to 2016 with a horizontal resolution of $2.8^{\circ} \times 2.8^{\circ}$ and $60 \mathrm{lev}-$ els from the surface to $\sim 60 \mathrm{~km}$. The model contained 11 parameterised $\mathrm{CCl}_{4}$ tracers that evolved in response to surface emissions and loss by calculated atmospheric photolysis rates and specified partial lifetimes with respect to uptake by oceans or soils (see Table 2). Different tracers (CTC1-CTC8) use different specified combinations of the emission and loss processes described below. Tracer CTC1 is the reference tracer with the current best estimate values of the loss processes. The annually varying global emissions were derived with the global one-box model used in recent WMO ozone assessments (for details, see Velders and Daniel, 2014), assuming a 35-year total lifetime for $\mathrm{CCl}_{4}$, and the long-term surface observations of $\mathrm{CCl}_{4}$ from the NOAA Global Monitoring Division (GMD) network (Hall et al., 2011). These emissions were distributed spatially according to Xiao et al. (2010).

For the photolysis sink, monthly-mean photolysis rates were calculated using a stand-alone version of the TOMCAT/SLIMCAT stratospheric chemistry scheme and kinetic data from Sander et al. (2011). Hourly model output was averaged to produce monthly-mean photolysis rates as a function of latitude and altitude. To assess the model sensitivity to the photolytic loss, two model tracers used these rates changed by $\pm 10 \%$, in line with the recommended combined uncertainty in cross sections and quantum yields from Sander et al. (2011). In reality this will be a lower limit of uncertainty in the modelled photolysis rates because it does not account for errors in the model radiative transfer code, ozone distribution etc. This is difficult to quantify absolutely, but we would note that the TOMCAT/SLIMCAT photolysis scheme has performed well in intercomparisons of radiative transfer codes (e.g. SPARC CCMVal, 2010; Sukhodolov et al., 2016). For comparisons using a prescribed ozone profile and solar fluxes, SPARC CCMVal (2010) found excellent agreement between models for the calculation of photolysis rates for $\mathrm{N}_{2} \mathrm{O}$ and CFC-11, which are species with similar photolysis sinks to $\mathrm{CCl}_{4}$. Therefore, we would suggest that the largest uncertainty in the modelled $\mathrm{CCl}_{4}$ photolysis rate does indeed come from the combined uncertainty in cross sections and quantum yields with a smaller contribution, maybe around $5 \%$, from uncertainties in the model ozone distribution and other factors such as the $\mathrm{O}_{3}$ absorption cross sections. 
Table 2. Summary of the TOMCAT 3-D CTM simulated $\mathrm{CCl}_{4}$ tracers.

\begin{tabular}{|c|c|c|c|c|c|c|}
\hline \multirow[t]{2}{*}{ Tracer } & \multirow[t]{2}{*}{$\begin{array}{l}\text { Emissions } \\
\left(\mathrm{Gg}_{\text {year }}{ }^{-1}\right)^{\mathrm{b}}\end{array}$} & \multicolumn{2}{|c|}{$\begin{array}{c}\text { Atmospheric loss } \\
\text { photolysis }\end{array}$} & \multicolumn{2}{|c|}{$\begin{array}{c}\text { Surface loss } \\
\text { partial lifetimes } \\
\text { (years) }\end{array}$} & \multirow[t]{2}{*}{$\begin{array}{l}\text { Overall } \\
\text { lifetime } \\
\text { (years) }^{\mathrm{a}}\end{array}$} \\
\hline & & $\begin{array}{l}\text { Photochemical } \\
\text { data }\end{array}$ & $\begin{array}{r}\text { Partial } \\
\text { lifetime }^{\mathrm{a}}\end{array}$ & Ocean & Soil & \\
\hline CTC1 & 39.35 & JPL & 41.9 & 183 & 375 & 31.9 \\
\hline CTC1s & 39.35 & JPL & 41.9 & 210 & 375 & 31.9 \\
\hline СТC2 & 39.35 & JPL & 41.8 & 147 & 375 & 30.4 \\
\hline CTC2s & 39.35 & JPL & 41.8 & 157 & 375 & 30.4 \\
\hline CTC3 & 39.35 & JPL & 41.9 & 241 & 375 & 33.7 \\
\hline CTC3s & 39.35 & JPL & 41.9 & 313 & 375 & 33.7 \\
\hline CTC4 & 39.35 & JPL & 41.9 & 183 & 288 & 31.5 \\
\hline CTC5 & 39.35 & JPL & 41.9 & 183 & 536 & 32.4 \\
\hline CTC6 & 39.35 & $0.9 \times \mathrm{JPL}$ & 43.5 & 183 & 375 & 32.9 \\
\hline CTC7 & 39.35 & $1.1 \times \mathrm{JPL}$ & 40.4 & 183 & 375 & 31.1 \\
\hline СТC8 & 45.25 & JPL & 41.9 & 183 & 375 & 32.0 \\
\hline
\end{tabular}

The ocean sink was represented by specifying a partial lifetime of $\mathrm{CCl}_{4}$ with respect to removal from the surface grid boxes over the oceans. We used the recent results of Butler et al. (2016), who derived this partial lifetime to be 183 (147-241) years. (We also performed a simulation with the values presented in SPARC (2016) of 209 (157-313) years for tracers CTC1s, CTC2s and CTC3s). For the partial lifetime of $\mathrm{CCl}_{4}$ loss over soil we used the recently published values of Rhew and Happell (2016), i.e. a best estimate of 375 years and an uncertainty range of 288-536 years. Both the ocean and soil sinks were assumed to be constant in time and were treated to be spatially uniform over ocean and land grid boxes, respectively, following the method of Liang et al. (2014).

The TOMCAT run was spun up for 4 years, and then all tracers were scaled to match "observed" global mean $\mathrm{CCl}_{4}$ values in early 1996 (based on WMO/UNEP A1 scenario values, derived from an average of AGAGE and NOAA surface measurements). The model was then run for a further 20 years until 2016.

\section{Results}

\subsection{Emissions}

Figure 1 shows the evolution of the prescribed surface emissions in the model run (i.e. for tracers CTC1-CTC7) over 1995-2015. As noted in Sect. 2.5, these were derived from atmospheric observations and a global box model assuming a constant overall $\mathrm{CCl}_{4}$ lifetime of 35 years. For the purposes of this study, these prescribed emissions simply provide a time-dependent reference input dataset for the 3-

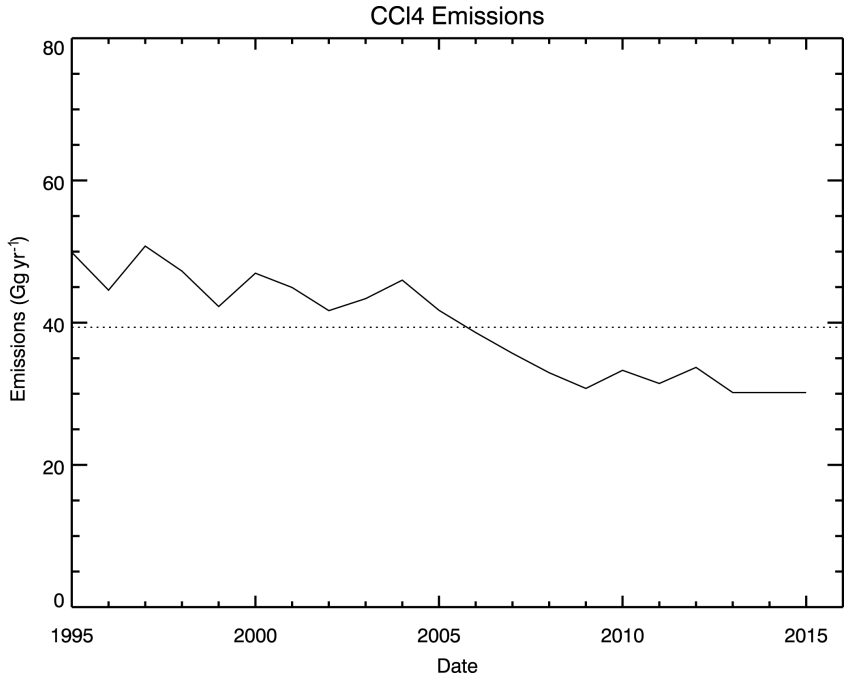

Figure 1. Time variation of global annual emissions $\left(\mathrm{Gg} \mathrm{year}^{-1}\right)$ derived from measured global atmospheric changes and a global box model (solid line). The emission record was used for the standard TOMCAT model experiments. The mean emissions over the period 1996-2015 are $39.35 \mathrm{Gg}_{\text {year }}{ }^{-1}$ (indicated by dotted line).

D model. Comparisons of the 3-D model with atmospheric observations can then provide further, more detailed information on the likely $\mathrm{CCl}_{4}$ lifetime and the emissions required to match the atmospheric observations. Note the inferred lifetime and emissions are model-dependent. Figure 1 shows that the prescribed emissions decrease from around 45 to about $35 \mathrm{Gg}_{\text {year }}{ }^{-1}$ with a more rapid decrease between 2004 and 2009. The mean over the whole period is 39.35 Gg year ${ }^{-1}$ (see dotted line). 


\subsection{Comparison with observations}

First we compare the simulated $\mathrm{CCl}_{4}$ tracers with observations to evaluate the performance of the basic model. Figure 2 compares model results (in green) with surface observations at eight sites from the NOAA (blue line) and AGAGE (red line) networks for which $\mathrm{CCl}_{4}$ data are available. Sites where measurements are reported by both networks - i.e. Mace Head, Trinidad Head, Samoa and Cape Grim - show that NOAA observations are larger than AGAGE by about $5 \mathrm{ppt}$ in 1996 , which decreases to about 1 ppt by 2014 . The panels also show global mean $\mathrm{CCl}_{4}$ values from the WMO (2014) A1 scenario (black line), which was constructed by a simple average of the global means derived with AGAGE and NOAA data, and therefore typically lies between the results from the two networks at these sites. Note that the TOMCAT runs were scaled globally to agree with the 2014 WMO/UNEP baseline scenario in 1996, which was derived from an average of results from the two networks. Figure 2 shows that $\mathrm{CCl}_{4}$ from the TOMCAT reference tracer CTC1 decays more rapidly than observed in the networks. By 2013 tracer CTC1 underestimates the WMO/UNEP scenario by about 8 ppt. Note that although we are using an updated emission dataset, which is derived from observations, the level of agreement also depends on the overall $\mathrm{CCl}_{4}$ lifetime specified or calculated in each model.

Figure 3 compares total column $\mathrm{CCl}_{4}$ from model run CTC1 with FTIR observations at Jungfraujoch. At present this is the only ground-based station with a long-term dataset for column $\mathrm{CCl}_{4}$. Although the geographical coverage is therefore limited, the comparison does allow us to test the modelled $\mathrm{CCl}_{4}$ through the depth of the troposphere and not just at the surface (as in Fig. 2). An initial comparison between the observed and modelled columns indicated a bias of about $15 \%$, with TOMCAT lying below the FTIR data. Since the latter could be affected by a systematic uncertainty of up to $10-11 \%$ (see Table 1 in Rinsland et al., 2012), we allowed for a $\times 0.9$ scaling of the column amounts. Figure 3 shows the model still tends to underestimate the scaled FTIR column by about $0.05 \times 10^{15}$ molecules $\mathrm{cm}^{-2}$ (about $5 \%$ ). This difference is similar to that between the NOAA and AGAGE observed surface mixing ratios in the 1990s and early 2000s, so this limits the extent to which we can assess the consistency of the surface and column observations. Despite any disagreements in the absolute amount of observed $\mathrm{CCl}_{4}$, the relative decay rates can still be compared. The FTIR column observations show a decline of $1.3 \times 10^{13}$ molecules cm ${ }^{-2}$ year $^{-1}\left(1.18 \%\right.$ year $\left.^{-1}\right)$, which compares fairly well with the modelled value (control tracer CTC1) of $1.5 \times 10^{13}$ molecules $\mathrm{cm}^{-2}$ year ${ }^{-1}$ $\left(1.36 \%\right.$ year $\left.^{-1}\right)$. Therefore, it appears that the model slightly overestimates the observed relative decay of column $\mathrm{CCl}_{4}$ as well as the relative decline rate measured at the surface (1.1$1.2 \%$ year $^{-1}$ from 1996 to 2013).
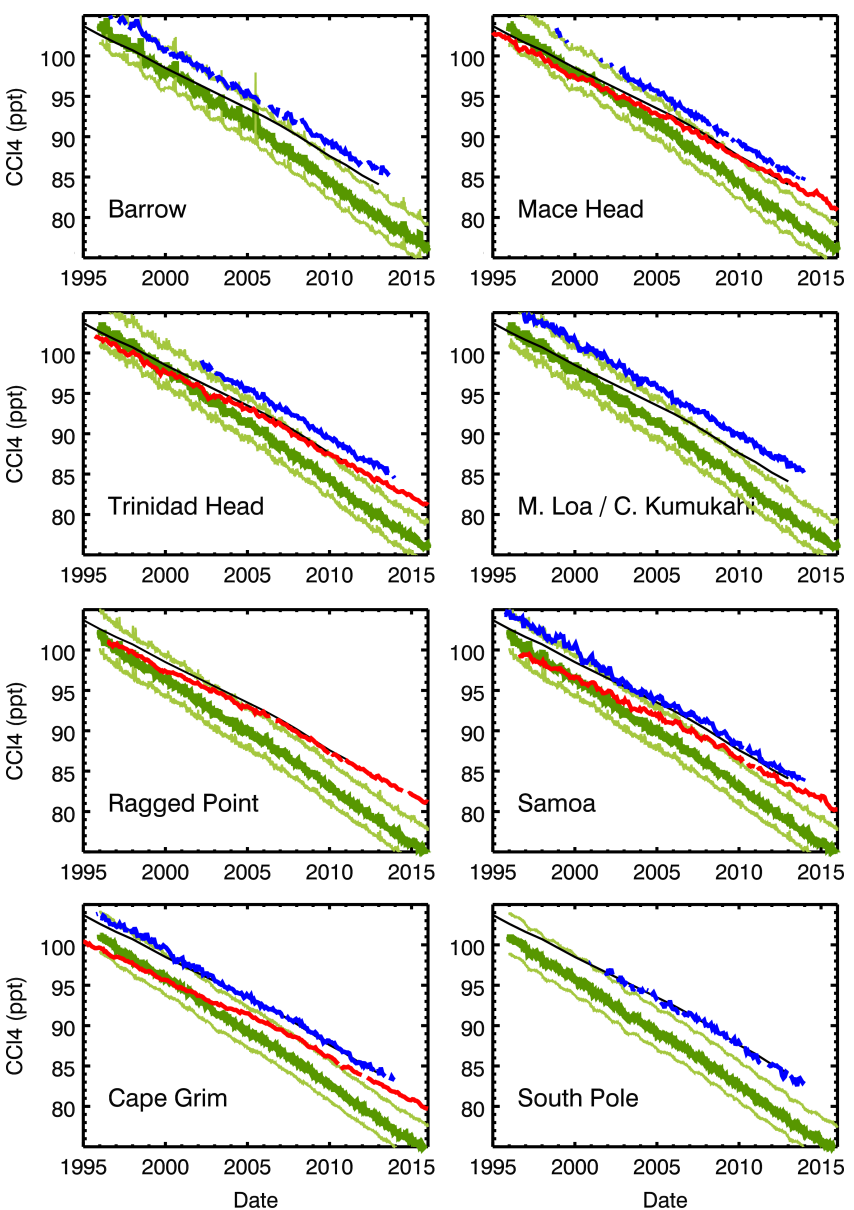

Figure 2. Comparison of modelled surface $\mathrm{CCl}_{4}$ concentration (ppt) with observations at eight stations in the AGAGE (red line) or NOAA (blue line) networks. Also shown is the $\mathrm{CCl}_{4}$ global mean surface mixing ratio from WMO (2014) scenario A1 (black line). The dark green line shows model control tracer CTC1, and light green lines show this tracer CTC 1 line displaced by +3 and $-2 \mathrm{ppt}$ to aid comparisons with the slope of the NOAA and AGAGE observations. This range is arbitrary but indicates how the model line would be displaced if the CTC1 tracer had been initialised to agree with either the NOAA or AGAGE global mean $\mathrm{CCl}_{4}$ abundance in 1996.

The HIPPO campaigns provided flask sampling of air at a wide range of latitudes from the surface to about $14 \mathrm{~km}$. Figure 4 shows a comparison of the results from the analysis of flasks collected during HIPPO from the surface to $1.5 \mathrm{~km}$ altitude from five campaigns from January 2009 until September 2011. Also shown are results from model tracers CTC1 (control) and CTC8 (increased emissions), along with the monthly-mean observations from NOAA and AGAGE surface stations. Comparisons between the model and HIPPO observations are summarised in Table 3. Consistent with the results from the surface network, the HIPPO results show larger $\mathrm{CCl}_{4}$ mixing ratios in the Northern Hemisphere than the Southern Hemisphere. There is some variability 
Table 3. Summary of model-measurement comparisons for boundary layer (surface-1.5 km) $\mathrm{CCl}_{4}$ observations during HIPPO aircraft missions.

\begin{tabular}{|c|c|c|c|c|c|}
\hline $\begin{array}{l}\text { TOMCAT } \\
\mathrm{CCl}_{4} \text { tracer }\end{array}$ & $\begin{array}{r}\text { Mean bias } \\
\text { (model-obs.) } \\
(\mathrm{ppt})\end{array}$ & $\begin{array}{r}\text { Mean bias } \\
\text { (model-obs.) } \\
(\%)\end{array}$ & $\begin{array}{r}\text { Observed } \\
\text { hemispheric } \\
\text { gradient (ppt) }\end{array}$ & $\begin{array}{r}\text { Modelled } \\
\text { hemispheric } \\
\text { gradient (ppt) }\end{array}$ & $\begin{array}{r}\text { Correlation } \\
\text { coefficient }(r)\end{array}$ \\
\hline \multicolumn{6}{|c|}{ HIPPO-1 (January 2009) } \\
\hline CTC1 & -3.2 & -3.6 & 1.1 & 1.6 & 0.8 \\
\hline CTC8 & -0.4 & -0.5 & 1.1 & 1.8 & 0.8 \\
\hline \multicolumn{6}{|c|}{ HIPPO-2 (November 2009) } \\
\hline CTC1 & -3.4 & -3.8 & 1.3 & 1.4 & 0.6 \\
\hline CTC8 & -0.5 & -0.6 & 1.3 & 1.6 & 0.6 \\
\hline \multicolumn{6}{|c|}{ HIPPO-3 (March/April 2010) } \\
\hline CTC1 & -3.8 & -4.3 & 1.0 & 1.6 & 0.5 \\
\hline CTC8 & -0.9 & -1.0 & 1.0 & 1.8 & 0.5 \\
\hline \multicolumn{6}{|c|}{ HIPPO-4 (June/July 2011) } \\
\hline CTC1 & -4.3 & -4.9 & 1.4 & 1.1 & 0.6 \\
\hline CTC8 & -1.2 & -1.4 & 1.4 & 1.2 & 0.6 \\
\hline \multicolumn{6}{|c|}{ HIPPO-5 (August/September 2011) } \\
\hline CTC1 & -3.9 & -4.5 & 1.6 & 1.0 & 0.7 \\
\hline CTC8 & -0.9 & -1.0 & 1.6 & 1.2 & 0.7 \\
\hline
\end{tabular}

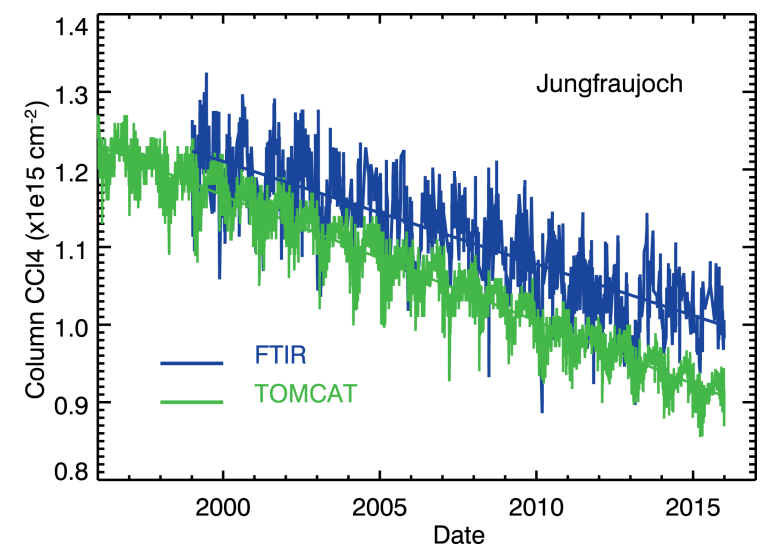

Figure 3. Time series of total column $\mathrm{CCl}_{4}$ $\left(\times 10^{15}\right.$ molecules $\left.\mathrm{cm}^{-2}\right)$ at the Jungfraujoch NDACC station, Switzerland $\left(46.5^{\circ} \mathrm{N}, 8^{\circ} \mathrm{E}\right)$ (blue line). The observations have been scaled by 0.9 to account for a possible high bias in the $\mathrm{CCl}_{4}$ retrieved columns (see Sect. 3.2). Also shown are results from model control tracer CTC1 (green line). The straight lines are the linear fits to the observations and model output.

in the HIPPO observations, but this is larger in HIPPO-3 (March/April 2010), for example, than in HIPPO-1 (January 2009). The HIPPO campaigns occurred when the difference between the surface NOAA and AGAGE observations had decreased but is still apparent (Figs. 2 and 4). It appears that the NOAA observations, which are larger than AGAGE, are in better agreement with the HIPPO data at locations where both surface networks sampled $\left( \pm 1^{\circ}\right.$ of latitude), but note that the HIPPO data are reported on the NOAA calibration scale. For example, across all of the HIPPO campaigns, the mean bias (NOAA minus HIPPO) is $<0.1,-0.1$ and $0.2 \mathrm{ppt}$ at MHD, SMO and CGO, respectively. Similarly, for AGAGE at these sites, the mean bias is $-1.7,-1.6$ and $-1.4 \mathrm{ppt}$, respectively. For the near-surface values plotted in Fig. 4, the model qualitatively captures the interhemispheric gradient (see Sect. 3.3 for more discussion). Tracer CTC1 underestimates the HIPPO observations, with a mean campaign bias in the range of -3.6 to $-4.9 \%$ (Table 3 ). The agreement is improved by assuming additional emissions in tracer CTC8 (see also Fig. 2), which has a smaller mean bias in the range of -0.5 to $-1.4 \%$.

Figure 5 shows HIPPO-TOMCAT comparisons in the upper troposphere-lower stratosphere (UTLS) at $12-14 \mathrm{~km}$. The model captures the latitudinal gradient in the observations, including the large decreases at high latitudes in stratospheric air. This high-latitude agreement is worst in the northern polar region in November 2009 and the southern polar region in June/July 2011, when the comparisons are likely to be affected by structure in the tracer fields caused by large gradients around the polar vortex. Nevertheless, Fig. 5 shows that the model performs realistically in terms of transport of $\mathrm{CCl}_{4}$ to higher altitudes and through the lower stratosphere to high latitudes. 


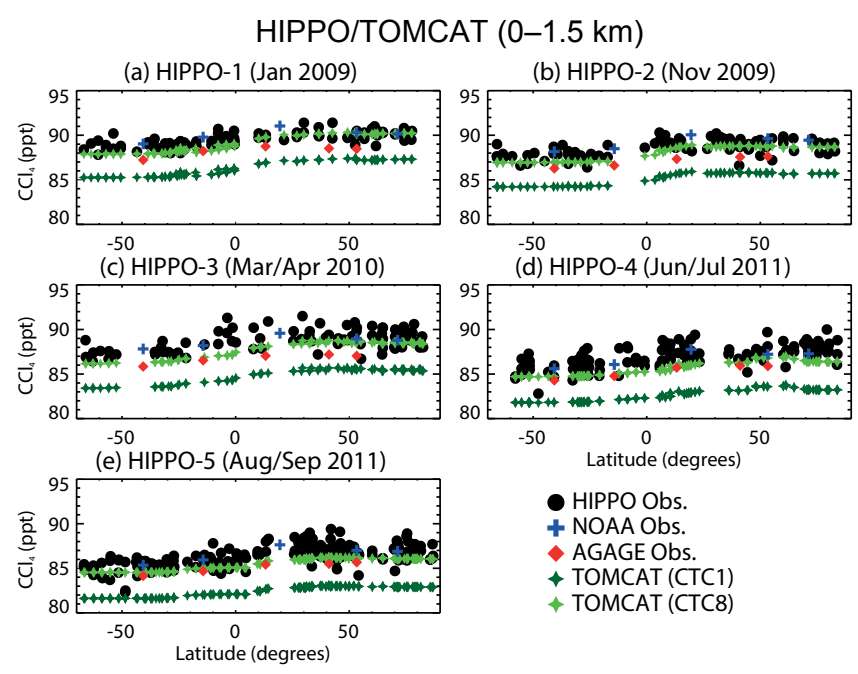

Figure 4. Latitude cross section of HIPPO observations of $\mathrm{CCl}_{4}$ (ppt, black circles) between the surface and $1.5 \mathrm{~km}$ altitude from flights during five campaigns between January 2009 and September 2011. Also shown are mean surface observations from the AGAGE (red diamond) and NOAA (blue + ) networks (see Table 1 and Fig. 2) for the months of the campaign. Results from model tracers CTC1 and CTC8 are also shown.

Comparison with $\mathrm{CCl}_{4}$ profiles in the stratosphere allows us to test how well the model simulates the photolysis sink. Figure 6 compares mean modelled profiles of $\mathrm{CCl}_{4}$ with the recent ACE-FTS research retrievals (Harrison et al., 2016) from March to April 2005 in three latitude bands. The figure shows results from the control tracer CTC1 along with the tracers CTC6 and CTC7, which have $\pm 10 \%$ change in photolysis rate. Overall the model reproduces the observed decay of $\mathrm{CCl}_{4}$ in the stratosphere well, which confirms that the stratospheric photolysis sink and transport are well modelled in TOMCAT, with a reasonable corresponding lifetime. However, the difference between tracer CTC 1 and tracers CTC6/CTC7 is not large compared to the model-ACE differences. Hence, while the available ACE data can confirm the basic realistic behaviour of the model in the stratosphere, they are not able to evaluate the model more critically. When available over the duration of the ACE mission, the full $\mathrm{v} 4$ retrieval will allow more comprehensive and critical comparisons over a wider range of latitudes and seasons. Also, Fig. 6 illustrates the need to compare the model transport separately through comparison of other tracers with different lifetimes and distributions, before factoring the effect of photolytic loss of $\mathrm{CCl}_{4}$.

\subsection{Impact of uncertainties in sinks}

Figure 7 shows the partial $\mathrm{CCl}_{4}$ photolysis lifetime diagnosed from reference tracer CTC1. There is large short-term (monthly) variability in the instantaneous lifetime. Even for the annual mean lifetime there is significant interannual vari-
HIPPO/TOMCAT (12-14 km)
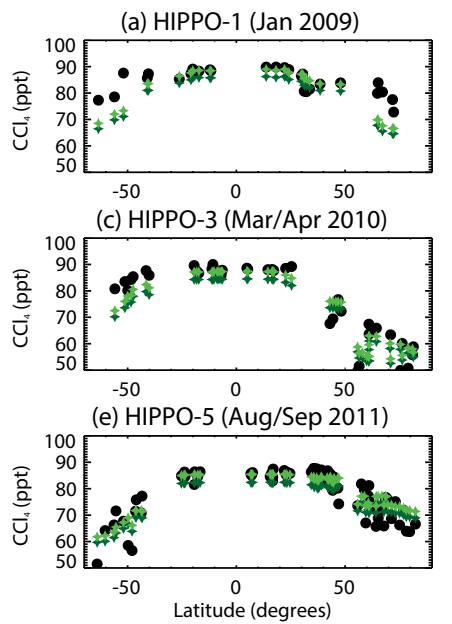

(b) HIPPO-2 (Nov 2009)

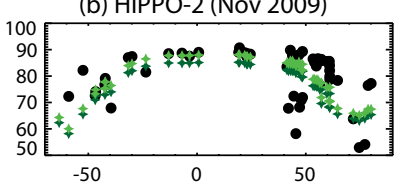

(d) HIPPO-4 (Jun/Jul 2011)

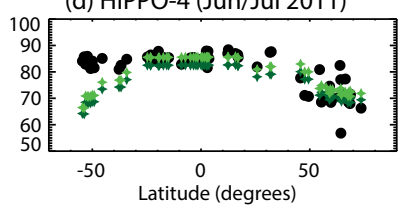

- HIPPO Obs.

+ TOMCAT (CTC1)

+ TOMCAT $($ CTC8)

Figure 5. Latitude cross section of HIPPO observations of $\mathrm{CCl}_{4}$ (ppt, black circles) between 12 and $14 \mathrm{~km}$ altitude from flights during five campaigns between January 2009 and September 2011. Results from model tracers CTC1 and CTC8 are also shown.

ability which is driven by interannual meteorological variability. The diagnosed annual mean $\mathrm{CCl}_{4}$ lifetime over this period varies from around 39.5 years in 2010 to around 46 years in 2008. The impact of the meteorological variability was confirmed by running the model for 4 years with annually repeating meteorology from two different years $(2008$ and 2010). The results of these runs are shown by the + symbols, which show constant annual mean partial lifetimes but with a large ( $\sim 7$ year) difference. This $\sim 7$-year difference in the photolysis partial lifetime would correspond to a $\sim 4$-year difference in the overall atmospheric lifetime after combining with current best estimates of the ocean and soil sinks. This difference in overall lifetime will translate into a difference of $\sim 6 \mathrm{Gg} \mathrm{year}^{-1}$ in the emissions required to match the observations. Therefore, this circulation-driven variability can significantly influence top-down emission estimates and their interannual changes. This also shows the derived mean emission estimates will be model- and/or meteorologydependent, and need to be treated with caution.

Table 2 shows the partial lifetimes specified (ocean and soil) or calculated (photolysis) in the model runs. The atmospheric partial lifetimes were diagnosed from monthly-mean loss rates and monthly burdens, averaged over the model simulation. The partial lifetime for photolytic loss in the control tracer CTC1 is 41.9 years. This is somewhat smaller than the mean modelled partial lifetime in SPARC (2013) of 48.6 years, albeit consistent with the overall recommended value of 44 (36-58) years based on combined observations and models. Although two models in SPARC (2013) gave partial lifetimes around 41-42 years, the other five models gave values in the range 50.7 to 54.3. Therefore, it appears that the TOMCAT partial lifetime for loss by photolysis is at 


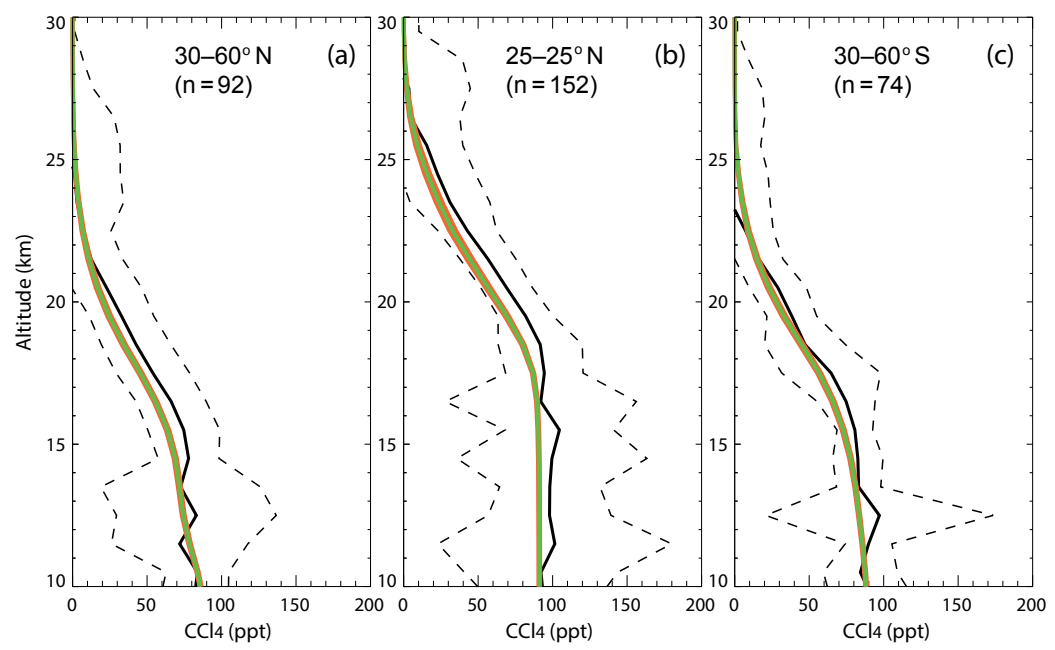

Figure 6. Mean profiles of $\mathrm{CCl}_{4}$ from March to April 2005 as determined from the recent ACE-FTS research retrievals (Harrison et al., 2016) (black line) for latitude bands (a) $30-60^{\circ} \mathrm{N}$, (b) $25^{\circ} \mathrm{S}-25^{\circ} \mathrm{N}$ and (c) $30-60^{\circ} \mathrm{S}$. The number of observed profiles which contribute to the mean is given in the titles $(n)$. The dashed lines show the standard deviation of the observations. Also shown are mean profiles from model control tracer CTC1 for the same latitude bins and time period (green line) and the range of values produced from sensitivity runs CTC6 and CTC7 with $\pm 10 \%$ change in $\mathrm{CCl}_{4}$ photolysis rate (orange shading, difficult to see). Note that the model profiles are averages over the indicated spatial regions and are not sampled at the exact locations of the ACE-FTS measurements.

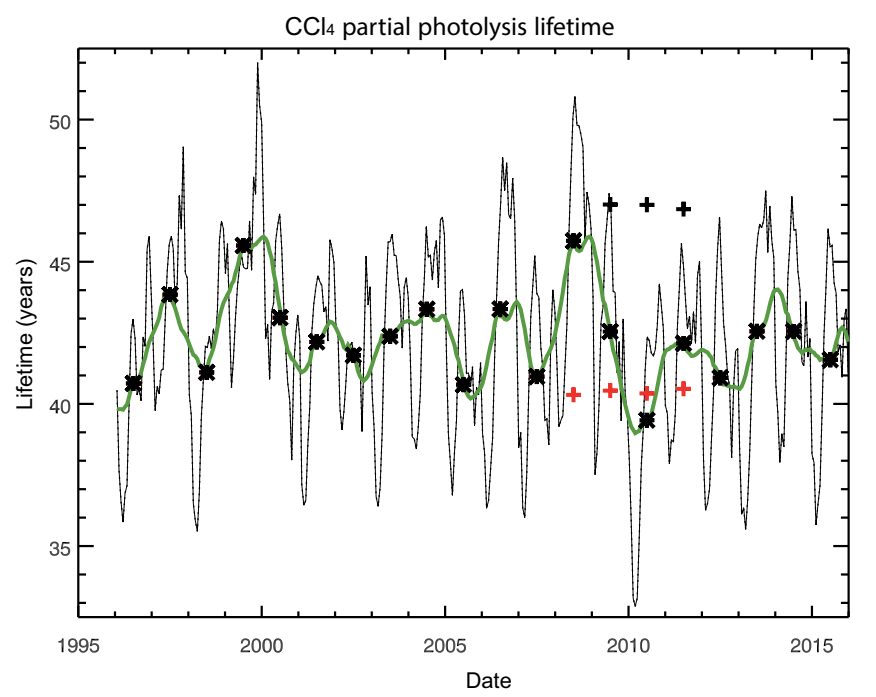

Figure 7. Modelled instantaneous $\mathrm{CCl}_{4}$ partial photolysis lifetime diagnosed from reference tracer CTC1 (dotted line, value every 20 days) and the same curve with 1-year smoothing (green solid line). The $*$ symbols indicate the annual mean $\mathrm{CCl}_{4}$ partial lifetime from this tracer. Also shown are annual mean lifetime results from 4-year simulations (2008-2011) with repeating winds for 2008 (black +) and $2010($ red +) meteorology.

the younger end of the modelled range, which is consistent with a slightly young stratospheric age of air in this version of the TOMCAT/SLIMCAT model when forced with ERAInterim reanalyses (Chipperfield, 2006; Monge-Sanz et al., 2007). Table 2 shows that, as expected, changing the magni- tude of the soil and ocean sink does not affect the calculated photolysis partial lifetime.

Figure 8a shows the comparison of control model tracer CTC1 vs. global mean surface observations, along with model sensitivity tracers CTC2 and CTC 3 with minimum/maximum estimates for the ocean sink. This global comparison of tracer CTC1 shows similar behaviour to the individual stations in Fig. 2; the control run slightly overestimates the observed rate of decay (for the level of emissions assumed). The uncertainty in the ocean sink has a large relative impact on the decay rate of $\mathrm{CCl}_{4}$, relative to the mismatch with the AGAGE and NOAA datasets. Figure $8 \mathrm{a}$ also shows results from tracers CTC1s, CTC2s and CTC $3 \mathrm{~s}$, which use the best estimate and range of the ocean loss lifetimes from the SPARC (2016) report. The partial lifetime used for CTC1s (210 years) gives a slower decay than tracer CTC1, which uses the latest recommended value (183 years). The uncertainty range between tracers CTC2s and CTC $3 \mathrm{~s}$ is also slightly larger than between CTC 2 and CTC 3 . These tracers are included for comparison with the SPARC (2016) report, though we reiterate that the values published in Butler et al. (2016) are the latest recommendations for the ocean sink.

Figure $8 \mathrm{~b}$ is a similar plot which uses model tracers CTC 4 and CTC5 to investigate the impact of uncertainty in the soil loss rate. Here the impact on the modelled $\mathrm{CCl}_{4}$ decay rate is relatively small due to the relatively long lifetime of $\mathrm{CCl}_{4}$ with respect to loss by soils.

Figure $8 \mathrm{c}$ shows the effect of a $\pm 10 \%$ change in photolysis rate on the modelled $\mathrm{CCl}_{4}$ decay using runs CTC6 and CTC7. Note that the diagnosed atmospheric lifetimes in 

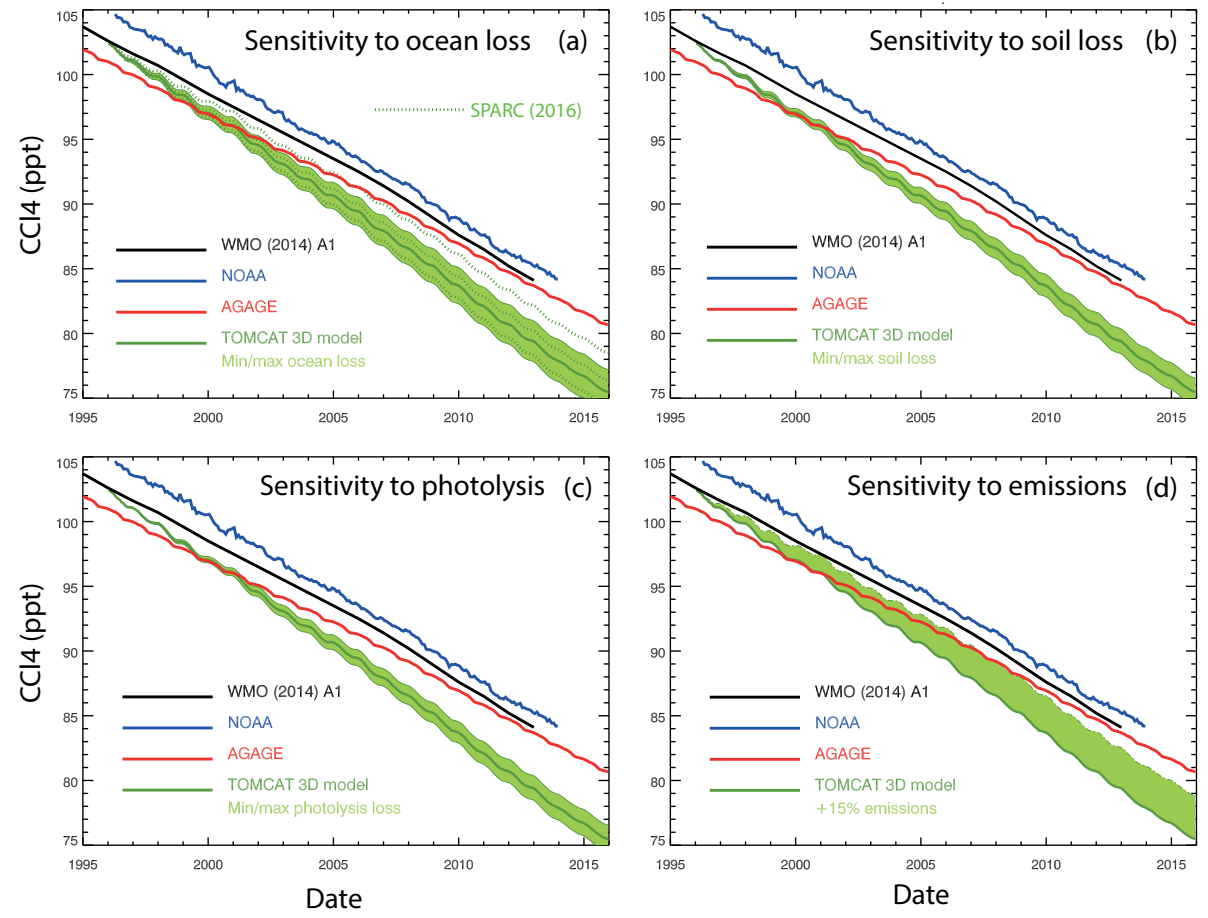

Figure 8. Observed global mean surface $\mathrm{CCl}_{4}$ from AGAGE (red) and NOAA (blue) networks, along with merged observational dataset from WMO (2014) scenario A1 (black line). These are compared with results from TOMCAT model run CTC1 (dark green line) and different sensitivity tracers in each panel with the range given as a light green band: (a) an ocean sink of 147 (tracer CTC2) and 241 (CTC3) years, (b) a soil sink of 288 (CTC4) and 536 (CTC5) years, (c) a $\pm 10 \%$ change in stratospheric photolysis (CTC6 and CTC7) and (d) a 15\% increase in emissions (CTC8). Note that in (d) the light green shading only shows an increase relative to control tracer CTC1 as the sensitivity tracer considered had increased emissions. Panel (a) also includes results from TOMCAT tracers which use the SPARC (2016) value for the ocean sink of 183 (CTC1s) years and the uncertainty range of 157 (CTC2s)-313 (CTC3s) years (green dashed lines).

these two runs change by a lot less than $10 \%$ (e.g. 41.9 to 43.5 years; $3.8 \%$ - see Table 2). This is due to compensation in the modelled chemical loss rates in the stratosphere $\left(J\left[\mathrm{CCl}_{4}\right]\right)$. A faster photolysis rate $J$ will decrease the concentration of $\mathrm{CCl}_{4}$, leading to a partial cancellation in the product. This would be a property of any source gas with a stratospheric sink and large tropospheric reservoir. This partial cancellation in the stratospheric loss rate means that uncertainty in the ocean sink still dominates. This is likely to be the case even with a much larger assumed uncertainty in the modelled photolysis rates (e.g. $\pm 20 \%$ ).

Figure 8d shows the results from tracer CTC8, which assumes $15 \%$ larger emissions than tracer CTC1. This increase in emissions (to a mean of around $45 \mathrm{Gg}$ year $^{-1}$ ) brings the model in closer agreement with the rates of decay seen in the surface networks, especially that depicted by the mean of NOAA and AGAGE observations. A $20 \%$ increase in emissions (to a mean of around $47 \mathrm{Gg}$ year $^{-1}$ ) would give even better agreement for this setup of the TOMCAT model (not shown). Over the period 1996-2015, the slopes of the linear fits to the lines for tracers CTC1 and CTC8 are -1.36 and $-1.20 \mathrm{ppt}_{\text {year }}{ }^{-1}$, respectively. This $0.16 \mathrm{ppt}_{\text {year }}{ }^{-1}$ difference in slope corresponds to a difference in emissions of
$6 \mathrm{Gg}$ year $^{-1}$ between the two tracers (Table 2). The linear fits to the global mean NOAA and AGAGE lines in Fig. 8d over the same period are -1.15 and -1.01 ppt year $^{-1}$, respectively, although it should be noted that the AGAGE variation is not linear over this time frame. Nevertheless, this 0.14 ppt year $^{-1}$ difference in the mean slope from the two surface networks (equivalent to $\sim 5 \mathrm{Gg}$ year $^{-1}$ emissions) is significant when compared to the magnitude of the emissions needed to fit the observations under different lifetime assumptions. Therefore, resolving this issue of the absolute difference in the concentrations reported by the two networks will be important for a detailed quantification of the $\mathrm{CCl}_{4}$ budget, and that work is ongoing.

Figure 8 shows that current uncertainty in the $\mathrm{CCl}_{4}$ sinks could account for some, but probably not all, modelobservation differences noted above and that better quantification of the ocean sink is important. Despite it being the most important overall sink, uncertainty in stratospheric photolysis is not that important, although it should be noted that the analysis presented in Fig. 8 does not take account of uncertainties in model transport and the methodology for calculating photolysis rates. Alternatively, model-observation agreement could also be closed by an increase in emissions, 
and our current best estimate of the partial $\mathrm{CCl}_{4}$ lifetimes would require emissions of around $47 \mathrm{Gg}_{\mathrm{year}}{ }^{-1}$ for TOMCAT.

\subsection{Interhemispheric gradient}

Figure 9 shows the observed interhemispheric gradient (IHG) in $\mathrm{CCl}_{4}$ derived from the NOAA and AGAGE networks along with results from model tracer CTC1. The observations show that the IHG decreased from about $1.5-2.0 \mathrm{ppt}$ around 2002 to $1.0-1.5 \mathrm{ppt}$ around 2010. Although both networks show this behaviour, the IHG from the NOAA network is persistently larger by about $0.3 \mathrm{ppt}$ than from the AGAGE network, except for the period 2006-2009, when the IHG values are similar. Throughout the period shown there is not much correspondence between the variations seen in the two observational records as the timing of the seasonal cycles is often different. The NOAA results, which are derived directly from low-frequency (1 per week) station observations, show more variability than the AGAGE results, which are derived from a 12-box model. The modelled IHG also shows a decreasing trend from around 2002 until 2012. However, the modelled IHG shows a regular annual cycle which does not match the observations. In the middle part of the period, when there is a discernible annual cycle in the IHG observed by both networks, the modelled annual cycle is out of phase. We have investigated whether the sparse sampling of the NOAA and AGAGE networks may be responsible for some of the differences between the observations and with the model. Figure 9 shows results of the model tracer CTC1 sampled like the AGAGE and NOAA networks (i.e. at the locations give in Table 1). Compared to using the whole model hemispheric grid, sampling at the station locations only changes the IHG slightly; for example the model's IHG sampled at the AGAGE sites is about 0.3 ppt larger than that sampled at the NOAA sites, which is in the opposite sense to the differences in the observations. However, the modelled annual cycle is still out of phase with the observations in the 2006-2010 period. Some information on the $\mathrm{CCl}_{4} \mathrm{IHG}$ is also given by the comparison with HIPPO data in Fig. 4 and Table 3. Over the course of the campaigns, which sample air over the Pacific, the IHG based on the HIPPO sampling varies from $1.0 \mathrm{ppt}$ in HIPPO-3 to $1.6 \mathrm{ppt}$ in HIPPO-5. This variation reflects seasonal variability rather than any long-term trend. Figure 9 shows that the model does not reproduce the timing of this variation.

Overall, Fig. 9 shows that there are still details in the $\mathrm{CCl}_{4}$ IHG that merit further investigation. There are limitations of the TOMCAT model setup used in this study. The assumed emission distribution (from Xiao et al., 2010) is likely not a good representation of reality. The Xiao et al. (2010) emissions are based on population densities, while more recent regional inversion studies suggest that $\mathrm{CCl}_{4}$ emissions originate mainly from chemical industrial regions and are not linked to major population centres (Vollmer et al., 2009; Hu

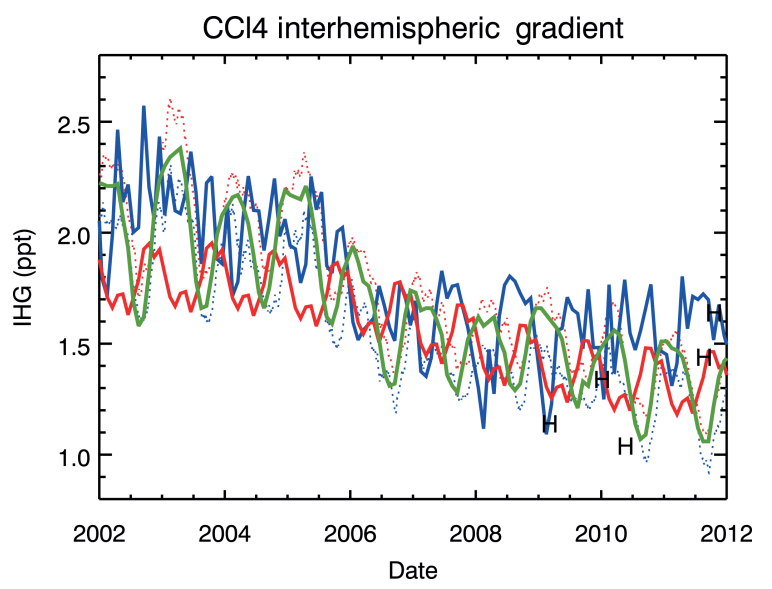

Figure 9. Observed interhemispheric gradient (IHG) of $\mathrm{CCl}_{4}$ (north-south, ppt) from monthly-mean AGAGE (red line) and NOAA (blue line) observations. The NOAA IHG is estimated by binning the station data by latitude and applying a cosine(latitude) weighting. The AGAGE IHG is estimated from output of a 12-box model which assimilates the observations. Also shown are results from the model tracer CTC1 sampled over the whole model domain (green line), sampled at the AGAGE station locations (red dotted line) and sampled at the NOAA station locations (blue dotted line). The H symbols show the IHG estimated from the five HIPPO campaigns (see Table 3).

et al., 2016; Graziosi et al., 2016). This will affect the model IHG, especially when sampled at the limited surface station locations of either network. Also, the model does not have a seasonally or spatially varying ocean sink which is likely to contribute to the poor agreement. An accurate simulation of the $\mathrm{CCl}_{4} \mathrm{IHG}$ and its time variations remains as an important way to test for our understanding of the $\mathrm{CCl}_{4}$ budget.

\section{Conclusions}

We have used the TOMCAT 3-D chemical transport model to investigate the rate of decay of atmospheric $\mathrm{CCl}_{4}$. In particular we have studied the impact of uncertainties in the rates of $\mathrm{CCl}_{4}$ removal by photolysis, deposition to the ocean and deposition to the soils on its predicted decay. The model results have been compared with surface-based in situ and total column observations, aircraft measurements, and the available satellite profiles.

Using photochemical data from Sander et al. (2011), and lifetimes for removal by the ocean and soils of 183 and 375 years, respectively, the model shows that main sinks contribute to $\mathrm{CCl}_{4}$ loss in the following proportions: photolysis, $74 \%$; ocean loss, $17 \%$; and soil loss, $8 \%$. A $10 \%$ uncertainty in the combined photolysis cross section and quantum yield has only a modest impact on the rate of modelled $\mathrm{CCl}_{4}$ decay, partly due to the limiting effect of the rate of transport of $\mathrm{CCl}_{4}$ from the main tropospheric reservoir to the stratosphere, where photolytic loss occurs. The model shows un- 
certainties in ocean loss have the largest impact on modelled $\mathrm{CCl}_{4}$ decay due to its significant contribution to the loss and large uncertainty range (147 to 241 years). The impact of uncertainty in the minor soil sink is relatively small.

With an assumed $\mathrm{CCl}_{4}$ emission rate of $39 \mathrm{Gg}_{\mathrm{gear}}{ }^{-1}$ the control model with the best estimate of loss processes still underestimates the observed $\mathrm{CCl}_{4}$ over the past 2 decades (i.e. overestimates the atmospheric decay). Changes to the $\mathrm{CCl}_{4}$ loss processes, in line with known uncertainties, could bring the model into agreement with observations, as could an increase in emissions to around $47 \mathrm{Gg}_{\text {year }}{ }^{-1}$. Our results are consistent with those of Liang et al. (2014), who used different combinations of emission estimates and lifetimes to obtain good agreement between their 3-D model and $\mathrm{CCl}_{4}$ observations. For example, their model run $\mathrm{C}$ used emissions of $50 \mathrm{Gg} \mathrm{year}{ }^{-1}$ with an overall lifetime of 30.7 years. Here we find a need for smaller mean emissions due to our larger overall $\mathrm{CCl}_{4}$ lifetime, which in turn is due to updated estimates of the ocean and soil sinks. We note that, as TOMCAT calculates a smaller partial photolysis lifetime compared to some other 3-D models (see SPARC, 2013; Chipperfield et al., 2014), the required emissions could be slightly less than suggested by our simulations.

From a model point of view, improved knowledge of the $\mathrm{CCl}_{4}$ emissions required to reproduce observations will depend on better quantification of the modelled partial atmospheric lifetime. Although uncertainties in the photochemical data are small, there are model-dependent parameterisations of transport and radiative transfer which can affect the atmospheric partial lifetime significantly. Studies with multiple 3-D models could be used to address this.

\section{Data availability}

The output from the TOMCAT model experiments can be obtained by emailing Martyn Chipperfield.

Acknowledgements. This work was supported by the UK Natural Environment Research Council (NERC) through the TROPHAL project $(\mathrm{NE} / \mathrm{J} 02449 \mathrm{X} / 1)$. The TOMCAT modelling work was supported by the NERC National Centre for Atmospheric Science (NCAS). The ACE-FTS $\mathrm{CCl}_{4}$ work was supported by the NERC National Centre for Earth Observation (NCEO). The ACE mission is funded primarily by the Canadian Space Agency. The University of Liège involvement has primarily been supported by the F.R.S.-FNRS, the Fédération Wallonie-Bruxelles and the GAW-CH programme of Meteoswiss. Emmanuel Mahieu is a research associate with F.R.S.-FNRS. We thank the International Foundation High Altitude Research Stations Jungfraujoch and Gornergrat (HFSJG, Bern) for supporting the facilities needed to perform the FTIR observations and the many colleagues who contributed to FTIR data acquisition. AGAGE is supported principally by NASA (USA) grants to MIT and SIO, as well as by Department of Energy and Climate Change (DECC, UK) and NOAA (USA) grants to Bristol University and by CSIRO and BoM (Australia).
The operation of the station at Mace Head was funded by DECC through contract GA01103. Martyn P. Chipperfield is supported by a Royal Society Wolfson Merit award. Qing Liang is supported by the NASA Atmospheric Composition Campaign Data Analysis and Modeling (ACCDAM) programme. NOAA observations were made possible with technical and sampling assistance from station personnel (D. Mondeel, C. Siso, C. Sweeney, S. Wolter, D. Neff, J. Higgs, M. Crotwell, D. Guenther, P. Lang and G. Dutton) and were supported, in part, through the NOAA Atmospheric Chemistry, Carbon Cycle, and Climate (AC4) programme. Elliot L. Atlas acknowledges X. Zhu and L. Pope for technical support and the National Science Foundation AGS Program for support under grants ATM0849086 and AGS0959853.

Edited by: R. Müller

Reviewed by: two anonymous referees

\section{References}

Allen, N. D. C., Bernath, P. F., Boone, C. D., Chipperfield, M. P., Fu, D., Manney, G. L., Oram, D. E., Toon, G. C., and Weisenstein, D. K.: Global carbon tetrachloride distributions obtained from the Atmospheric Chemistry Experiment (ACE), Atmos. Chem. Phys., 9, 7449-7459, doi:10.5194/acp-9-7449-2009, 2009.

Bernath, P. F.: The Atmospheric Chemistry Experiment (ACE), J. Quant. Spectrosc. Ra., 186, 3-16, doi:10.1016/j.jqsrt.2016.04.006, 2017.

Brown, A. T., Chipperfield, M. P., Boone, C., Wilson, C., Walker, K. A., and Bernath, P. F.: Trends in atmospheric halogen containing gases since 2004, J. Quant. Spectrosc. Ra., 112, 2552-2566, doi:10.1016/j.jqsrt.2011.07.005, 2011.

Burkholder, J. B., Mellouki, W., Fleming, E. L., George, C., Heard, D. E., Jackman, C. H., Kurylo, M. J., Orkin, V. L., Swartz, W. H., and Wallington, T. J.: Evaluation of Atmospheric Loss Processes, Chap. 3 of SPARC Report on the Lifetimes of Stratospheric Ozone-Depleting Substances, Their Replacements, and Related Species, edited by: Ko, M., Newman, P., Reimann, S., and Strahan, S., SPARC Report No. 6, WCRP-15/2013, 2013.

Butler, J. H., Yvon-Lewis, S. A., Lobert, J. M., King, D. B., Montzka, S. A., Bullister, J. L., Koropalov, V., Elkins, J. W., Hall, B. D., Hu, L., and Liu, Y.: A comprehensive estimate for loss of atmospheric carbon tetrachloride $\left(\mathrm{CCl}_{4}\right)$ to the ocean, Atmos. Chem. Phys., 16, 10899-10910, doi:10.5194/acp-1610899-2016, 2016.

Carpenter, L. J., Reimann, S., Burkholder, J. B., Clerbaux, C., Hall, B. D., Hossaini, R., Laube, J. C., and Yvon-Lewis, S. A.: OzoneDepleting Substances (ODSs) and Other Gases of Interest to the Montreal Protocol, Chap. 1 in Scientific Assessment of Ozone Depletion: 2014, Global Ozone Research and Monitoring Project - Report No. 55, World Meteorological Organization, Geneva, Switzerland, 2014.

Chipperfield, M. P.: New version of the TOMCAT/SLIMCAT offline chemical transport model: Intercomparison of stratospheric tracer experiments, Q. J. Roy. Meteor. Soc., 132, 1179-1203, 2006.

Chipperfield, M. P., Liang, Q., Abraham, L., Bekki, S., Braesicke, P., Dhomse, S., Di Genova, G., Fleming, E. L., Hardiman, S., Iachetti, D., Jackman, C. H., Kinnison, D. E., Marchand, M., 
Pitari, G., Rozanov, E., Stenke, A., and Tummon, F.: Evaluation of Atmospheric Loss Processes, Chap. 5 of SPARC Report on the Lifetimes of Stratospheric Ozone-Depleting Substances, Their Replacements, and Related Species, edited by: Ko, M., Newman, P., Reimann, S., and Strahan, S., SPARC Report No. 6, WCRP-15/2013, 2013.

Chipperfield, M. P., Q. Liang, S. E. Strahan, O. Morgenstern, S. S. Dhomse, N. L. Abraham, A. T. Archibald, S. Bekki, P. Breasicke, G. Di Genova, E. F. Fleming, S. C. Hardiman, D. Iachetti, C. H. Jackman, D. E. Kinnison, M. Marchand, G. Pitari, J. A. Pyle, E. Rozanov, A. Stenke, F. Tummon, Multi-model estimates of atmospheric lifetimes of long-lived Ozone-DepletingSubstances: Present and future, J. Geophys. Res., 119, 25552573, doi:10.1002/2013JD021097, 2014.

Dee, D. P., Uppala, S. M., Simmons, A. J., Berrisford, P., Poli, P., Kobayashi, S., Andrae, U., Balmaseda, M. A., Balsamo, G., Bauer, P., Bechtold, P., Beljaars, A. C. M., van de Berg, L., Bidlot, J., Bormann, N., Delsol, C., Dragani, R., Fuentes, M., Geer, A. J., Haimberger, L., Healy, S. B., Hersbach, H., Hólm, E. V., Isaksen, L., Kållberg, P., Köhler, M., Matricardi, M., McNally, A. P., Monge-Sanz, B. M., Morcrette, J.-J., Park, B.-K., Peubey, C., de Rosnay, P., Tavolato, C., Thépaut, J.-N., and Vitart, F.: The ERA-Interim reanalysis: configuration and performance of the data assimilation system, Q. J. Roy. Meteor. Soc., 137, 553-597, doi:10.1002/qj.828, 2011.

Graziosi, F., Arduini, J., Bonasoni, P., Furlani, F., Giostra, U., Manning, A. J., McCulloch, A., O’Doherty, S., Simmonds, P. G., Reimann, S., Vollmer, M. K., and Maione, M.: Emissions of carbon tetrachloride from Europe, Atmos. Chem. Phys., 16, 1284912859, doi:10.5194/acp-16-12849-2016, 2016.

Hall, B. D., Dutton, G. S., Mondeel, D. J., Nance, J. D., Rigby, M., Butler, J. H., Moore, F. L., Hurst, D. F., and Elkins, J. W.: Improving measurements of $\mathrm{SF}_{6}$ for the study of atmospheric transport and emissions, Atmos. Meas. Tech., 4, 2441-2451, doi:10.5194/amt-4-2441-2011, 2011.

Happell, J. D. and Roche, M. P.: Soils: a global sink of atmospheric carbon tetrachloride, Geophys. Res. Lett., 30, 1088, doi:10.1029/2002GL015957, 2003.

Happell, J. D., Mendoza, Y., and Goodwin, K.: A reassessment of the soil sink for atmospheric carbon tetrachloride based on flux chamber measurements, J. Atmos. Chem., 71, 113-123, 2014.

Harrison, J. J., Boone, C. D., and Bernath, P. F.: New and improved infrared absorption cross sections and ACE-FTS retrievals of carbon tetrachloride $\left(\mathrm{CCl}_{4}\right)$, J. Quant. Spectrosc. Ra., 186, 139-149, doi:10.1016/j.jqsrt.2016.04.025, 2016.

Hu, L., Montzka, S. A., Miller, B. R., Andrews, A. E., Miller, J. B., Lehman, S. J., Sweeney, C., Miller, S., Thoning, K., Siso, C., Atlas, E., Blake, D., de Gouw, J. A., Gilman, J. B., Dutton, G., Elkins, J. W., Hall, B. D., Chen, H., Fischer, M. L., Mountain, M., Nehrkorn, T., Biraud, S. C., Moore, F., and Tans, P. P.: Continued emissions of carbon tetrachloride from the U.S. nearly two decades after its phase-out for dispersive uses, P. Natl. Acad. Sci., 113, 2880-2885, doi:10.1073/pnas.1522284113, 2016.

Krysell, M., Fogelqvist, E., and Tanhua, T.: Apparent removal of the transient tracer carbon tetrachloride from anoxic seawater, Geophys. Res. Lett., 21, 2511-2514, doi:10.1029/94GL02336, 1994.

Liang, Q., Newman, P. A., Daniel, J. S., Reimann, S., Hall, B. D., Dutton, G., and Kuijpers, L. J. M.: Constraining the car- bon tetrachloride $\left(\mathrm{CCl}_{4}\right)$ budget using its global trend and inter-hemispheric gradient, Geophys. Res. Lett., 41, 5307-5315, doi:10.1002/2014GL060754, 2014.

Monge-Sanz, B., Chipperfield, M. P., Simmons, A., and Uppala, S.: Mean age of air and transport in a CTM: Comparison of different ECMWF analyses, Geophys. Res. Lett., 34, L04801, doi:10.1029/2006GL028515, 2007.

O’Doherty, S., Simmonds, P. G., Cunnold, D. M., Wang, H. J., Sturrock, G. A., Fraser, P. J., Ryall, D., Derwent, R. G., Weiss, R. F., Salameh, P., Miller, B. R., and Prinn, R. G.: In situ chloroform measurements at Advanced Global Atmospheric Gases Experiment atmospheric research stations from 1994 to 1998, J. Geophys. Res., 106, 20429-20444, doi:10.1029/2000JD900792, 2001.

Prinn, R., Weiss, R., Fraser, P., Simmonds, P., Cunnold, D., Alyea, F., O’Doherty, S., Salameh, P., Miller, B., and Huang, J.: A history of chemically and radiatively important gases in air deduced from ALE/GAGE/AGAGE, J. Geophys. Res., 105, 1775117792, 2000.

Prinn, R. G., Weiss, R. F., Fraser, P. J., Simmonds, P. G., Cunnold, D. M., O’Doherty, S., Salameh, P. K., Porter, L. W., Krummel, P. B., Wang, R. H. J., Miller, B. R., Harth, C., Greally, B. R., Van Woy, F. A., Steele, L. P., Mühle, J., Sturrock, G. A., Alyea, F. N., Huang, J., and Hartley, D. E.: The ALE/GAGE AGAGE Network, Carbon Dioxide Information Analysis Center (CDIAC), Oak Ridge National Laboratory (ORNL), US Department of Energy (DOE), 2016.

Rhew, R. C. and Happell, J. D.: The atmospheric partial lifetime of carbon tetrachloride with respect to the global soil sink, Geophys. Res. Lett., 43, 2889-2895, doi:10.1002/2016GL067839, 2016.

Rigby, M., Prinn, R. G., O’Doherty, S., Miller, B. R., Ivy, D., Mühle, J., Harth, C. M., Salameh, P. K., Arnold, T., Weiss, R. F., Krummel, P. B., Steele, L. P., Fraser, P. J., Young, D., and Simmonds, P. G.: Recent and future trends in synthetic greenhouse gas radiative forcing, Geophys. Res. Lett., 41, 2623-2630, doi:10.1002/2013GL059099, 2014.

Rinsland, C. P., Mahieu, E., Demoulin, P., Zander, R., Servais, C., and Hartmann, J.-M.: Decrease of the carbon tetrachloride $\left(\mathrm{CCl}_{4}\right)$ loading above Jungfraujoch, based on high resolution infrared solar spectra recorded between 1999 and 2011, J. Quant. Spectrosc. Ra., 113, 1322-1329, doi:10.1016/j.jqsrt.2012.02.016, 2012.

Sander, S. P., Friedl, R. R., Abbatt, J. P. D., Barker, J. R., Burkholder, J. B., Golden, D. M., Kolb, C. E., Kurylo, M. J., Moortgat, G. K., Wine, P. H., Huie, R. E., and Orkin, V. L.: Chemical Kinetics and Photochemical Data for Use in Atmospheric Studies Evaluation Number 17, JPL Publication, 10-6, Jet Propulsion Laboratory, Pasadena, USA, 2011.

Simmonds, P. G., Cunnold, D. M., Weiss, R. F., Prinn, R. G., Fraser, P. J., McCulloch, A., Alyea, F. N., and O'Doherty, S.: Global trends and emission estimates of carbon tetrachloride $\left(\mathrm{CCl}_{4}\right)$ from in-situ background observations from July 1978 to June 1996, J. Geophys., Res., 103, 16017-16028, 1998.

SPARC: Lifetimes of stratospheric ozone-depleting substances, their replacements and related species, SPARC Report no. 6, WCRP-15/32013, 2013.

SPARC: Report on the mystery of carbon tetrachloride, SPARC Report no. 7, WCRP-13/2016, 2016. 
SPARC CCMVal (Stratospheric Processes And their Role in Climate): Report on the Evaluation of Chemistry-Climate Models, edited by: Eyring, V., Shepherd, T. G., and Waugh, D. W., SPARC Report No. 5, WCRP-132, WMO/TD-No. 1526, 2010.

Sukhodolov, T., Rozanov, E., Ball, W. T., Bais, A., Tourpali, K., Shapiro, A. I., Telford, P., Smyshlyaev, S., Fomin, B., Sander, R., Bossay, S., Bekki, S., Marchand, M., Chipperfield, M. P., Dhomse, S., Haigh, J. D., Peter, T., and Schmutz, W.: Evaluation of the simulated photolysis rates and their response to solar irradiance variability, J. Geophys. Res., 121, 6066-6084, 2016.

Velders, G. J. M. and Daniel, J. S.: Uncertainty analysis of projections of ozone-depleting substances: mixing ratios, EESC, ODPs, and GWPs, Atmos. Chem. Phys., 14, 2757-2776, doi:10.5194/acp-14-2757-2014, 2014.

Vollmer, M. K., Zhou, L. X., Greally, B. R., Henne, S., Yao, B., Reimann, S., Stordal, F., Cunnold, D. M., Zhang, X. C., Maione, M., Zhang, F., Huang, J., and Simmonds, P. G.: Emissions of ozone-depleting halocarbons from China, Geophys. Res. Lett., 36, L15823, doi:10.1029/2009GL038659, 2009.

WMO: Scientific Assessment of Ozone Depletion: 2014, Global Ozone Research and Monitoring Project - Report No. 55, 416 pp., Geneva, Switzerland, 2014.

Wofsy, S. C.: HIAPER Pole-to-Pole Observations (HIPPO): finegrained, global-scale measurements of climatically important atmospheric gases and aerosols, Philos. T. R. Soc. A, 369, 20732086, doi:10.1098/rsta.2010.0313, 2011.
Wofsy, S. C., Daube, B. C., Jimenez, R., Kort, E., Pittman, J. V., Park, S., Commane, R., Xiang, B., Santoni, G., Jacob, D., Fisher, J., Pickett-Heaps, C., Wang, H., Wecht, K., Wang, Q.-Q., Stephens, B. B., Shertz, S., Watt, A. S., Romashkin, P., Campos, T., Haggerty, J., Cooper, W. A., Rogers, D., Beaton, S., Hendershot, R., Elkins, J. W., Fahey, D. W., Gao, R. S., Moore, F., Montzka, S. A., Schwarz, J. P., Perring, A. E., Hurst, D., Miller, B. R., Sweeney, C., Oltmans, S., Nance, D., Hintsa, E., Dutton, G., Watts, L. A., Spackman, J. R., Rosenlof, K. H., Ray, E. A., Hall, B., Zondlo, M. A., Diao, M., Keeling, R., Bent, J., Atlas, E. L., Lueb, R., and Mahoney, M. J.: HIPPO aircraftdata, HIPPO Combined Discrete Flask and GC Sample GHG, Halo-, Hydrocarbon Data (R_20121129), Carbon Dioxide Infor-mation Analysis Center, Oak Ridge National Laboratory, OakRidge, Tennessee, USA, doi:10.3334/CDIAC/hippo_012, 2012.

Xiao, X., Prinn, R. G., Fraser, P. J., Weiss, R. F., Simmonds, P. G., O'Doherty, S., Miller, B. R., Salameh, P. K., Harth, C. M., Krummel, P. B., Golombek, A., Porter, L. W., Butler, J. H., Elkins, J. W., Dutton, G. S., Hall, B. D., Steele, L. P., Wang, R. H. J., and Cunnold, D. M.: Atmospheric three-dimensional inverse modeling of regional industrial emissions and global oceanic uptake of carbon tetrachloride, Atmos. Chem. Phys., 10, 10421-10434, doi:10.5194/acp-10-10421-2010, 2010. 